\title{
Fosil Plaj ve Kumulların Yüzey Altı Yapılarının İncelenmesinde Elektrik Özdirenç Tekniği ve Paleo-Kıyı Ortamı Yorumuna Katkısı
}

Electrical Resistivity Technique On The Investigation Of Subsurface Structure Of Fossil And Beach Dunes And Its Contributions To The Interpretation Of Paleo-Coastal Environment

\author{
Alper DEMIRCI ${ }^{1}$, Yunus Levent EKINCI' ${ }^{2}$, \\ Ahmet Evren ERGINAL ${ }^{3}$, Muhammed Zeynel ÖZTÜRK ${ }^{4}$ \\ ${ }^{l}$ Bitlis Eren Üniversitesi, Mühendislik Mimarlık Fakültesi, Jeofizik Mühendisliği Bölümü \\ ademirci@beu.edu.tr \\ ${ }^{2}$ Bitlis Eren Üniversitesi, Fen Edebiyat Fakültesi, Arkeoloji Bölümü ylekinci@beu.edu.tr \\ ${ }^{3}$ Ardahan Üniversitesi, Insani Bilimler Fakültesi, Coğrafya Bölümü aerginal@gmail.com \\ ${ }^{4}$ Niğde Üniversitesi, Fen Edebiyat Fakültesi, Coğrafya Bölümü muhammed.zeynel@gmail.com
}

öz

Teknolojik ilerlemelere bağlı olarak, bilgisayar yazılımları ve çoklu-elektrot ölçüm sistemlerindeki gelişmeler Elektrik Özdirenç Tomografi (EÖT) çalışmalarının hızlı ve güvenilir bir şekilde ve yerbilimlerinin farklı alanlarında kullanılmasına olanak sağlamıştır. Bu çalışmada özellikle sı̆̆ yeraltı yapısının aydınlatılması amacıyla oldukça sık kullanılan EÖT tekniğinin alışılagelmiş uygulama alanlarının dışında kıyı araştırmalarındaki kullanım avantajlarına yer verilmiştir.

Kıyılarda dalga, akıntı ve rüzgar denetimli olarak istiflenen ve ardından kalsiyum karbonat çimento ile birbirine bağlanan tabakalı kıyı çökellerinin plaj ve kumul kumları (veya diğer örtü birimleri) altında kalan kısımlarının ve bunların da örttüğü gömülü jeolojik yapı ve fosil topografyaların görüntülenmesi EÖT tekniğinin kıyı jeolojisi ve paleo-coğrafyası araştırmalarına verdiği önemli katkılar arasındadır.

Bu çalışmada Karadeniz (Şile, Karaburun, Kıyıöy) ve Ege Denizi (Bozcaada) kıyılarında gerçekleştirilen EÖT uygulamalardan elde edilen bulgular sunulmuştur. Geç Pleyistosen'den Geç Holosen'e kadar farklı jeolojik evrelerde çökelen ve çimentolanan bu fosil kıyı istiflerinin yüzey altı geometrileri, dokunak ilişkileri ve depolanma özellikleri oluştukları dönemin deniz seviyesi değişimleri ve paleo-rüzgar, akıntı dinamiklerinin daha iyi anlaşılması açısından önemli ipuçları sunmaktadır. Sunulan arazi öneklerinden elde edilen EÖT görüntüleri, çalışılan tabakaların derindeki (örtülü) kısımlarının çökelme ortamının anlaşılmasına katkı koyduğunu göstermektedir.

Anahtar Kelimeler: Deniz seviyesi değişimleri, EÖT, kıyı çökelleri, paleo-coğrafya 


\section{ABSTRACT}

Based on the technological progress, the improvements of the software packages and multi-electrode measuring systems have enabled to perform the Electrical Resistivity Tomography (ERT) measurements more widely, faster and more reliable in various disciplines of earth sciences. Herein, some recent case study examples performed by ERT technique for uncommon-purposes such as investigation of coastal environs are presented.

Imaging the lower parts of the beach and dune sands (or other covering units) of layered coastal deposits, which were cemented with calcium carbonate after the development by the control of wave, current and wind, and also the buried geological structures and fossil topographies covered by those beach and dune sands, shows significant contribution of ERT technique on the investigations of coastal geology and paleogeography. Thus some case studies, which have been performed in Black Sea (Şile, Karaburun, Klyı köy) and Aegean Sea (Bozcaada Island) coasts, and their findings were presented here.

The depositional characteristics, subsurface geometry and contact relations of those fossil coastal deposits cemented on different geological periods from Late Pleistocene to Late Holocene provide noteworthy contributions in understanding regarding sea level changes, paleo-wind and current dynamics. The derived-ERT images obtained from the field studies yielded key information about the depositional nature of the deeper parts of the studied layers.

Keywords: Coastal deposits, ERT, paleo-geography, Sea level changes

\section{GIRIŞ}

Bu çalışmada Elektrik Özdirenç Tomografi (EÖT) tekniğinin çimentolanmış fosil plajlar (yalıtaşları), kumul istifleri (eolinitler) ve çimentolanmış kokinalı kıyı istifleri (kokunitler) gibi kıyı istiflerinin çökelme derinlikleri, tabaka kalınlıkları, örten ve örtülen jeolojik birimlerle dokunak ilişkileri, gömülü fosil topoğrafyanın morfolojik yapıs1 gibi hususlarda sağladığı avantajlara değinilmektedir. Aşağıda, jeomorfolojik ve jeolojik çalışmalara EÖT tekniğinin katkısı üzerine örnek çalışmalar sunulmadan önce çalışılan her bir istifin petrografik, sedimantolojik ve diyajenetik özellikleri hakkında detaylı bilgi verilmiştir. Çalışmada sunulan EÖT görüntüleri yazarların son birkaç yılda farklı kıyı ortamlarından elde ettiği ve yayınladığı görüntülerden seçilmiştir.

Eolinit. Birçok orta enlem kıtaları ve adaları üzerinde gelişen rüzgâr denetimli özel kıyı birikim şekillerinden (Brooke 2001) olan eolinitler karasal koşullarda rüzgârlarla taşınan karbonat oranı yüksek ve karbonat çimentolu kumlar olarak adlandırılmıştır Frébourg vd. (2008). McLaren (2004) tarafindan rüzgârla birlikte taşınma ve depolanma süreçleri sonucunda oluşan çimentolanmış kumtaşı, Brooke (2001) tarafindan ise kıyı ortamında depolanmış karbonat çimentolu kıyı kireçtaşı şeklinde ifade edilmiştir. Amerika' da eolianite, Hindistan ve Orta Doğu'da miliolite, İsrail'de kurkar, Güney Afrika'da dunerock ve Akdeniz'de gres dunaire gibi dünyanın farklı kesimlerinde farklı şekillerde isimlendirilen bu fosil kumul oluşumları $60^{\circ}$ kuzey enlemlerine kadar görülebilmekle birlikte (McLaren 2004), her iki yarımkürede $20^{\circ}$ ile $40^{\circ}$ enlemleri arasında yaygın bir şekilde (\% 85) bulunmaktadır. Kalınlıkları $0.5 \mathrm{~m}$ ile $150 \mathrm{~m}$ arasında değişen eolinitler genellikle Kuvaterner (Pleyistosen), nadiren ise Kuvaterner öncesine aittir (Brooke 2001). Dünyanın en uzun eolinit depolarını 
içeren Avustralya kıyılarındaki çalışmalara göre karbonat çökeliminin büyük bölümü Kuvaterner boyunca birçok kez gerçekleşen interglasiyal ve interstadiyal dönemlerdeki yüksek deniz seviyeleri sırasında gerçekleşmiştir (Loope 2009). Benzer sonuçlara Bahamalar ve Bermuda'da bulunan eolinitler üzerindeki çalışmalarda da ulaşılmıştır. Bununla birlikte az da olsa özellikle son buzul dönemine tarihlendirilen eolinitler de bulunmaktadır. Bu tür depoların bulunduğu alanlar buzul dönemlerinin günümüzden daha kuru ve rüzgârlı geçtiği yerlerdir (Brooke 2001). Eolinitler, kıy1larda (k1y1 eolinitleri) ve karaların iç kesimlerinde bulunan (continental) eolinitler olarak iki gruba ayrılırlar. Karaların iç kesimlerinde bulunan eolinitler, karasal depresyonları doldurmuş kumul birikintilerinin dağılmasıyla oluşan şekillerdir. Kıyı eolinitleri ise, plaj depolarının ve deniz seviyesinin alçak olduğu zamanlarda açığa çıkan gel-git altı sedimentlerin rüzgârla aşınımından türemiş materyallerden, yani karbonat ve kıyı sedimentlerinden oluşan büyük kumul kuşaklarının taşlaşması ile oluşurlar. Bu nedenle kıyı eolinitleri günümüz ya da eski kıyı çizgilerinin yakınında bulunurlar (McLaren 2004). Türkiye kıyılarında bu fosil kumulların varlığına dair az sayıda kayıt bulunmaktadır (Kıyak ve Erginal 2010; Polymeris vd. 2012; Erginal vd. 2013a, b).

Kokunit. Çimentolanmış kokinalar veya kokunitler de kıyılarda gözlenen çimentolanmış kıyı çökellerindendir. Allaby (2008) tarafından yüksek oranda iri kabuk yığınları içeren, kalsiyum karbonat ile çimentolanmış bir tür kırıntılı kireçtaşı olarak tanımlanmıştır. Kokunitler plajlar gibi yüksek enerjili denizel ortamlarda birikmelerinden dolayı iyi tabakalanma gösterirler (Scholle vd. 1983; Lovejoy 1998). Lovejoy (1998) tarafindan kokunitlerin düzlemsel ya da çapraz tabakalar içerdiği belirtilmiş ve tabakaların oluşmasında tabakalar arasındaki tane boyu, materyal bileşimi, özellikle kabuk oranı, çimentolanma miktarı, tabaka rengi, kabukların uzun eksenlerinin doğrultularındaki farkl1lıklar gibi faktörlerin etkili olduğu belirtilmiştir. Bazı durumlarda kokunitlerin yalıtaşları ile de benzer özelliklere sahip olduğu görülür. Örneğin Çin'in Haishan Adası'nın kokunitlerin oluşturmuş olduğu plaj çökelleri yalıtaşı (coquina beachrock) olarak isimlendirilmiştir (Shen vd. 2013). Türkiye Trakya'nın Karadeniz kıyılarında çimentolanmış kokunitlerin varlığına dair sadece bir kayıt bulunmaktadır (Erginal vd. 2012).

Yalıtaşı. Bir tür kıyı konglomerası veya kumtaşı bileşiminde olan yalıtaşları ise çoğunlukla tropikal ve subtropikal denizlerin gelgit içi zonlarında gelişen karbonat çimentolanması sonucunda oluşurlar (Ginsburg 1953; Bricker 1971; Neumeier 1998). 1960'lara kadar yalıtaşlarının sadece tropikal ve subtropikal kuşaklarda bulunduğu düşünülürken (Russell 1959), daha sonra 1lıman (Zenkovitch 1967; Rey vd. 2004), hatta soğuk kuşakta (Binkley vd. 1980; Kneale ve Viles 2000) dahi yayılış gösterebildiği belirlenmiştir. Yalıtaşı çalışmalarına göre bu fosil plaj oluşuklarının daha çok $0^{\circ}-40^{\circ}$ arasında, özellikle $20^{\circ}-40^{\circ}$ arasında bulunmas1, soğuk iklimlerin yalıtaşı oluşumu için çok uygun olmadığını gösterir (Vousdoukas, vd. 2007). Bu özelliği ile yalıtaşı, mikro gel-git genliğine sahip birçok sıcak tropikal ve subtropikal kıyıların temel jeomorfolojik unsurlarından birini oluşturur (Thomas 2009). Dünya kıyılarında yalıtaşı oluşumunun en yaygın olduğu kıyılardan birisi de Türkiye kıyılarıdır. Türkiye kıyılarındaki yalıtaşlarının dağılışı Avşarcan (1997) tarafından ele alınmış, öncesinde Teke (Spratt ve Forbes 1847), İskenderun Körfezi (Goudie 1966), Alanya (Bener 1974; Desruelles vd. 2009), Saros Körfezi (Erol 1972; Erginal vd. 2008), Bozcaada (Erginal 
vd. 2010), Marmara Denizi (Erginal 2012) ve Karadeniz (Erginal vd. 2013c) kıyılarında yalıtaşı oluşumları incelenmiştir. Yalıtaşları denize doğru genelde 10 dereceyi geçmeyecek şekilde eğimlidirler. Kıyı çizgisine paralel uzanırlar ve genellikle, oluştukları kıyı zonunun gel-git genliğine uyumlu olacak şekilde, kalınlıkları 1-2 metreyi geçmez. Ancak Alanya (Kelletat 2006) ve Bozcaada (Erginal vd. 2010) kiyılarında tespit edildiği üzere 3.5-4 metre arasında kalınlığa sahip olan örnekler de mevcuttur ki, bu durum gel-git arası kuşak dışında gel-git üstü kuşakta da çimentolanmanın olabilirliği üzerine tartışmaları başlatmıştır (Kelletat 2006). Aragonit ve yüksek magnezyum kalsit türünde karbonat polimorflarının çimentoladığı (Bricker 1971) yalıtaşı taneleri arasında gelişen farklı çimentolanma dokuları karbonat çökelimini denetleyen ana faktör olmakla birlikte diyajenez ortamının gerçek yeri hakkında da kayıtlar tutar. Bugüne dek yapılan araştırmalarda oluşum yaşları günümüzden önce 1000-5000 yıl arasında olup (Vousdoukas vd. 2007), Doğu Akdeniz kıyılarındaki örneklerin günümüzden 40002000 y1l öncesinde oluştukları bilinmektedir. Bu özellikleriyle Holosen deniz seviyesi değişimleri ve neotektonik araştırmalarda yalıtaşları anahtar oluşumlar olarak değerlendirilmektedir (Bezerra vd. 1998; Ramsay ve Cooper 2002; Kelletat 2006).

Aşınmadan korunmuş istiflerin kıyı boyunca uzanımları, tabaka doğrultu ve eğimleri, denize doğru devamları ve sualtında kalan kısımları saha gözlemleri ile kolaylıkla belirlenebilmektedir. $\mathrm{Bu}$ yüzlek veren tabakalardan çökelme ortamına veya fasiyes yorumuna ait detaylı bilgiler elde edilebilmektedir. Ancak, bu istiflerin yüzey altında erişebildikleri derinlik veya istif kalınlığı, istifin üzerindeki plaj materyalinin kalınlığı, istifin altındaki litolojik ve yapısal unsurların özellikleri ve gömülü tabakaların doğrultu ve eğim özellikleri gibi hususlar da çökelme ve/veya çimentolanma ve dolayısıyla diyajanetik ortama dair önemli bilgiler içermektedir. Özellikle istif kalınlığının belirlenmesi çok önemlidir. Çünkü, örneğin eolinitlerde belirlenebilen kalınlık çimentolanan eski kıyı kumulu sırtlarının toplam yüksekliğini, kokunit ve yalıtaşlarında belirlenen kalınlık ise çimentolanan plaj çökellerinin kalınlığını verecektir. Özellikle yalıtaşlarında oluşum ortamı gel-git içi zon olduğundan saha gözlemleri ile sadece yüzeylenmiş katmanlara göre kalınlık verilirse yanılg1 ortaya çıkacaktır. Oluşum ortamları, jenezi ve paleo-çevresel önemi ile dünya kıyılarındaki dağılışı konusunda yukarıda detaylı bilgi verilen bu çimentolanmış kıyı oluşukları hakkında yüzeyden herhangi bir kazı yapmadan jeofizik yöntemlerle oldukça detaylı ve doyurucu bilgilere erişmek mümkün olabilmektedir. $\mathrm{Bu}$ çalışmada, yazarlar tarafından daha önce Ege Denizi ve Karadeniz kıyılarında EÖT tekniği ile gerçekleştirilen yayınlanmış verilerin (Ekinci vd. 2010; Ekinci vd. 2012; Erginal vd. 2012; Erginal vd. 2013a, b ve c) bir derlemesi sunulmuştur. $\mathrm{Bu}$ çalışmalar sonucunda yukarıda değinilen özel kıy1 birikimlerine ait önemli bulgular izleyen bölümlerde verilmiştir.

\section{UYGULAMA ÖRNEKLERİ}

$\mathrm{Bu}$ bölümde; Bozcaada-Çanakkale, Karaburunİstanbul, Şile-İstanbul, K1yıköy-Kırklareli kıyılarında (Şekil 1) yapılan elektrik özdirenç çalışmaları ve elde edilen sonuçlara yer verilmiştir. Elektrik özdirenç çalışmalarında iki-boyutlu (2B) EÖT tekniği kullanılmış ve yeraltı yapısı aydınlatılmaya çalışılmıştır. Arazide 2B olarak toplanan görünür özdirenç verileri $2 \mathrm{~B}$ ters çözüm tekniği ile değerlendirilmiştir (Loke ve Barker 1996). Kullanılan algoritmada yeraltı dörtgen ağlarla sonlu sayıda sabit özdirenç değerleriyle temsil edilen hücrelere bölünmekte ve yinelemeli 
olarak ölçülen ve hesaplanan görünür özdirençler arasındaki fark indirgenmeye çalışılmaktadır. Algoritma, düzgünlük kısıtlı en küçük kareler (Sasaki 1992) temeline dayanan Quasi-Newton optimizasyon tekniğini (Loke ve Barker 1996) uygulamaktadır. Ayrıca, ters çözüm aşamasında L1 veya L2 normu kullanılabilmektedir (Loke ve Barker 1996). Bozcaada'da gerçekleştirilen çalışmada Iris-Syscal R1 Plus, diğer çalışma alanlarında ise GF ARES çoklu-elektrot özdirenç ölçüm sistemleri kullanılmıştır. Çalışma alanlarında bazı ölçüm hatları üzerinde bulunan belirgin topoğrafya farklarının da hesaplamalara katılabilmesi amacıyla her elektrotun bulunduğu noktanın kot yükseklikleri optik nivelman yardımı ile ölçülmüştür. Daha güvenilir ve detaylı sonuçlar elde etmek amacıyla ölçülen kot değerleri 2B ters çözüm işleminde hesaba katılmıştır.

\section{Bozcaada Eolinitleri}

Ege Denizi'nde Biga Yarımadası'nın batısında bulunan ve yaklaşı1k $36 \mathrm{~km}^{2}$ 'lik bir alana sahip olan Bozcaada (Şekil 1), karmaşık bir jeolojik yapıya sahiptir. Adanın GB kesiminde Zunguma Burnu olarak adlandırılan alan adada tarihlendirilmiş ve petrografisi ve çökelme yapıları ortaya konmuş tek Geç Pleyistosen yaşlı birimdir (Kıyak ve Erginal, 2010). Fosil kumul tabakalarından oluşan bu eolinitte dünya literatüründe de ilk uygulama olarak bir EÖT çalışması (Şekil 2a) gerçekleştirilmiştir (Ekinci vd. 2010; Erginal vd. 2013a).

Çalışma kapsamında, Geç Pleyistosen yaşlı Eolinit biriminin (Şekil 3a) yüzeyaltı yapısını ortaya koymak ve bu birimlerin altındaki Üst Miyosen yaşlı denizel çökellerle dokunak ilişkisini belirleyebilmek amaciyla, Wenner-Schlumberger

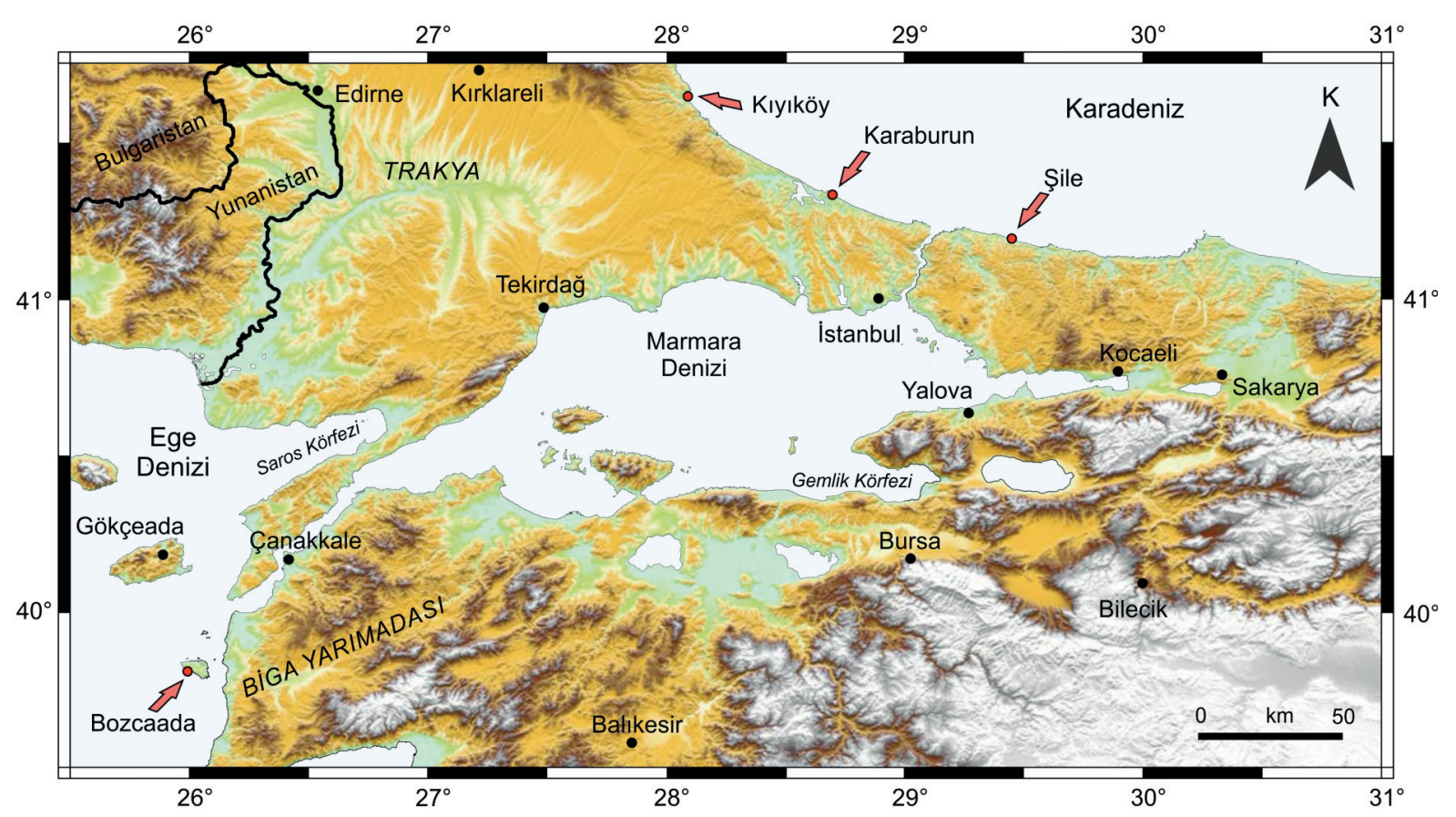

Şekil 1. Çalışma alanlarını gösteren yerbulduru haritası.

Figure 1. Location map of the study areas. 
dizilimi kullanılarak 3 m elektrot aralı̆̆ 1 , 14 derinlik seviyesi ve 35 elektrotlu ölçüm düzeni ile toplam 102 m'lik uzunluğa sahip bir hat boyunca 266 noktada görünür özdirenç değerleri elde edilmiştir (Şekil 2a). Bilindiği üzere, L1 normu (Robustbloklu) ters çözüm tekniği modeldeki konumsal farkların toplam mutlak değerlerini indirgemeye çalıştığından dolayı, keskin sınırlarla ayrılan veya kendi içinde homojen yapıya sahip jeolojik ortamlarda daha etkili çözüm üretmektedir (Loke vd. 2003). Dolayısıyla, çalışma alanının jeolojik özelliklerine uygun olarak, yüksek özdirenç değerleriyle temsil edilen Eolinit ve altındaki düşük özdirençli denizel çökeller arasındaki geçişin keskin olacağ1 öngörüsüyle elde edilen görünür özdirenç verilerinin ters çözümünde L1 normu kullanılmıştır. Ters çözüm işlemi 6 yineleme ve \% 3'lük mutlak hatayla sonlandırılmış ve yerelektrik model ortaya konmuştur (Şekil 4). Bir kaç ölçü noktası hariç, ölçülen ve hesaplanan görünür özdirenç değerlerinin logaritmik yüzdesel farklar sıfıra yakın küçük değerler almıştır. Dolayisıyla, elde edilen yerelektrik modelinin gerçek yeraltı yapısını yüksek oranda yansıttığını söylenebilir (Erginal vd. 2013a). GB-KD doğrultulu hat boyunca elde edilen yerelektrik model $17 \mathrm{~m}$ derinliğe kadar bilgi vermekte ve özdirenç değerlerinin yaklaşık olarak 5 ve 3580 ohm.m arasında değiştiği gözlenmektedir (Şekil 4). Yüksek özdirençli Üst Pleyistosen yaşlı eolinit birimleri, düşük özdirenç değerleri sunan Üst Miyosen yaşlı denizel çökellerden bariz bir şekilde ayırt edilebilmektedir. Ayrıca, denize doğru (GB yönünde) yaklaştıkça denizel çökellere ait özdirenç değerlerinde kademeli bir düşüş dikkat çekmektedir. Bu düşüş denize doğru gidildikçe çökel ortamındaki kil içeriğindeki artıştan kaynaklanabilir. Bunu saha gözlemleri de desteklemektedir. Ayrıca, kesitte KD yönünde ilerlendiğinde yatay mesafede yaklaşık 48. m'de gözlenen ve kilce zengin bölgeye kıyasla daha yüksek özdirenç değerlerine sahip bir alana geçilmektedir. $\mathrm{Bu}$ kesim yaklaşı 3-4 m'lik bir derinliğe sahiptir ve denizel çökellerin üst biriminde olasılıkla kumlu bir yüzeyi temsil etmektedir.

Yerelektrik kesitte açık bir şekilde gözlenen eolinit tabakalarının özdirenç değerleri yaklaşık olarak 700 ve 3580 ohm.m arasında değişmektedir (Şekil 4). Bu geniş özdirenç değişimi eolinitin kendi içerisinde homojen olmayan bir yapıda olduğunu ve eolinit içinde farklı boyutta erime boşluklarının varlığını gösterir. Ölçüm hattı boyunca eolinit tabakalarının kalınlığının da 4-7 m arasında olduğunu (Şekil 4) ve kum çökeliminin yatay bir topografya üzerinde gerçekleştiğini göstermektedir. Ayrıca kesitin 47. ve 52. m'ler arasındaki kısmında paleo-topografya yüzeyinde bir düzensizlik tespit edilmiştir (Şekil 4). Bu durum eolinit bloklarında lokal bir çökme veya yüksek açılı bir normal faydan kaynaklanmış olabilir (Ekinci vd. 2010; Erginal vd. 2013a). 


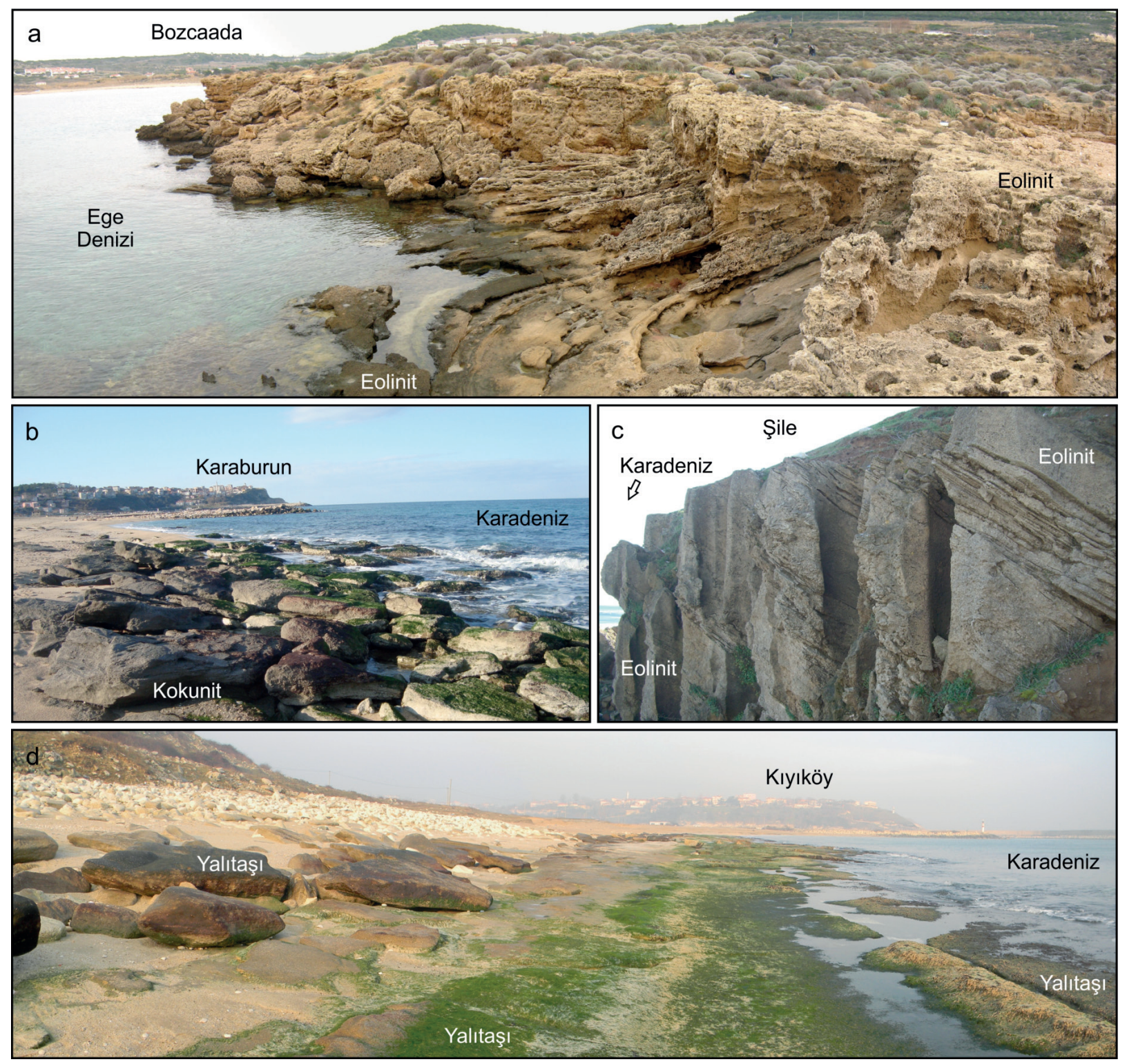

Şekil 2. EÖT çalışmalarının yapıldığı kıyı birikim şekillerinden bazı görünümler. a) Bozcaada eoliniti, b) Karaburun kokuniti, c) Şile eoliniti ve d) Kıyıköy yalıtaşı.

Figure 2. Some views from the coastal deposits where the ERT surveys were performed on. a) Bozcaada eolianites, b) Karaburun coquinites, c) Şile eolianites and d) Klyıköy beachrock. 


\section{Karaburun Kokuniti}

Karadeniz kıyısında yer alan çimentolanmış kokina istifi Marmara Denizi ve Karadeniz'i birbirine bağlayan İstanbul Boğazı'nın kuzey çıkışına yaklaşık $40 \mathrm{~km}$ uzaklıkta bulunmaktadır (Şekil 1). Çatalca Yarımadası'nın kuzeydoğu kıyısında bulunan Karaburun yerleşiminin doğu kıyısında kokunit blokları yüzeylenmektedir (Şekil 2b). Yaklaşık $4.5 \mathrm{~km}$ boyunca uzanan ve bivalv kırıntılarının meydana getirdiği biyojenik enkazdan oluşan kokina plajı kıyıdaki dalga kıranların varlığına bağlı olarak $20 \mathrm{~m}$ ile $60 \mathrm{~m}$ arasında değişen bir genişliğe sahiptir (Erginal vd. 2012).

Çalışma alanındaki kırıntılı kokina plajı altında bulunan kokunit tabakalarının enine ve boyuna uzanımı, kalınlığı, yüzey altı yapısı ve plaj materyalleri ile olan dokunak ilişkisi gibi parametrelerin ortaya çıkarılması amacıyla EÖT çalışması gerçekleştirilmiştir (Şekil 3b). Kıyı çizgisine dik, 40 m uzunluğunda ve aralarında 15 m uzaklık olacak şekilde üç hat (D1, D2 ve D3) ve kıyıya paralel $50 \mathrm{~m}$ uzunluğunda beş hat (P1, P2, P3, P4 ve P5) çalışma hatları olarak belirlenmiştir. Denize paralel olan hatlar arası mesafe, kokunit birimlerin yüzlek verdiği alanların genişliği göz önüne alınarak, P1-P2, P2-P3, P3-P4 ve P4-P5 arası için sırasıyla $6 \mathrm{~m}, 8 \mathrm{~m}, 6 \mathrm{~m}$ ve $8 \mathrm{~m}$ olacak şekilde belirlenmiştir. Ölçümler Dipol-dipol elektrot dizilimi kullanımıyla 9 derinlik seviyesi ve elektrot aralıkları $2 \mathrm{~m}$ ve $4 \mathrm{~m}$ olacak şekilde gerçekleştirilmiş ve toplam 1233 görünür özdirenç verisi toplanmıştır (Erginal vd. 2012).

Ters çözüm aşamasında, Bozcaada eolinitleri örneğinden farklı olarak L2 normu ters çözüm yaklaşımı kullanılmıştır. Bunun nedeni, diğer örnekteki keskin özdirenç geçişlerinin bu çalışmayı konu alan jeolojik birimler arasında beklenmemesidir. Deniz kıyısına paralel ve dik alınan 8 kesit incelendiğinde (Şekil 5 ve 6) 2 kesit hariç (P4 ve P5) tüm kesitlerin çalışma alanındaki çimentolanmış kokunit birimleri hakkında bilgi içerdiği gözlenmektedir. Yüzeyden yaklaşık $4.5 \mathrm{~m}$ derinliğe kadar bilgi veren yerelektrik kesitlerde yaklaşık 2 m kalınlığındaki kokunit kütleleri ile pekleşmemiş ve deniz suyuna doygun kokina plaj malzemesi arasındaki özdirenç değişimleri açıkça görülebilmektedir (Şekil 5 ve 6). Kesitler incelendiğinde, birkaç ölçü noktası hariç özdirenç değerlerinin 4 ila 1500 ohm.m arasında değiştiği gözlenmektedir. Tüm kesitlerde birimlerin daha iyi tanımlanması ve gözlenebilmesi amacıyla ortak renk skalası kullanılmıştır. Deniz kıyısına paralel olarak alınan P1, P2 ve P3 (Şekil 5) kesitlerinde " 2 " olarak işaretlenmiş kokunit birimleri sahip olduğu kısmen yüksek özdirenç değerleriyle, "1" ile işaretlenmiş ve daha derin kesimlerde bulunan düşük özdirençli plaj malzemesi ile bariz bir şekilde ayırt edilebilmektedir (Ekinci vd. 2012; Erginal vd. 2012). Özdirenç değerlerindeki bu düşüş deniz suyu girişimi nedeniyle oluşan tuzluluk artışından kaynaklanmaktadır. Diğer taraftan, P4 ve P5 kesitlerinde (Şekil 5) kokunit birimleri gözlenememekle birlikte, bu kesitlerde özdirenç değerlerindeki belirgin artışın tane boyutunun kıyıya daha yakın olan plaj malzemesinin aksine daha büyük ve dolayısıyla taneler arası boşluğun daha fazla olduğu plaj gerisindeki malzemeden kaynaklandığı düşünülmektedir. Deniz kıyısına dik olarak alınan D1, D2 ve D3 kesitleri (Şekil 6) boyunca topoğrafyanın belirgin bir şekilde değişmesi nedeniyle bu hatlarda yerelektrik kesitler topoğrafya etkisi göz önüne alınarak hesaplanmış ve sunulmuştur. Birbirine benzer belirtiler sunan bu kesitler incelendiğinde paralel kesitlerle yüksek oranda uyum içinde oldukları gözlenmektedir. Kokunit tabakalarının sonlandığ 1 yerden sonra özdirenç değerlerindeki ani artış bu kesimdeki suya doygun olmayan ve P5 kesitinde de açıkça görülen ve iri taneli kokina plaj malzemesi (4) ile ilişkilendirilmiştir. Şekil 6'da maksimum 
2 m kalınlığa sahip ve denizden karaya doğru yaklaşık 20-23 m kadar uzanan çimentolanmış tabakalar içeren kokunit yataklarının denize doğru $5^{\circ}$ ile $10^{\circ}$ 'lik açılar arasında eğimli olduğu görülmektedir. $\mathrm{Bu}$ sonuçlara göre çalışma alanında yüzlek veren çapraz tabakalı blokların gerçekte kaba kırıntılı kokinalı plaj ile örtülen kokunit tabakalarının üst seviyelerini oluşturdukları anlaşılmaktadır. Birimin mevcut deniz seviyesinden $2 \mathrm{~m}$ derinliğe kadar uzanması kokunitin oluşum mekanizmasını anlamak açısındanönemlibilgilervermiştir(Ekincivd. 2012; Erginal vd. 2012). Şöyle ki, gevşek yapılı kokina plaj1 altında gömülü bulunan $2 \mathrm{~m}$ kalınlığındaki kokunit, alçak deniz seviyesi koşullarındaki meteorik çimentolanma ile ilişkilidir. Bu durumda kokunit tabakalarının Karadeniz'in bugünkü seviyesine yakın olduğu dönemde biriktirildiği düşünülebilir. Bunu izleyen dönemde kavk1 kırıntılarının meteorik çimentolanması deniz seviyesinin günümüzden $2 \mathrm{~m}$ daha alçak olduğu bir dönemde gerçekleşmiştir. Tabakaların kokinalı plaj ve günümüz deniz seviyesinin altında bulunan derindeki kısımları, genç tabakaların çimentolanması sonrasında deniz seviyesinin sürekli yükseldiğini açıklamaktadır.

\section{Şile Eolinitleri}

İstanbul'un Şile ilçe merkezine yaklaşı $13 \mathrm{~km}$ uzaklıkta (batıda) bulunan eolinit istifi (Şekil 1) kumlu çakıllı ve biyojenik kırıntı içeren düşük eğimli bir plajın gerisinde (güneyinde) bulunmaktadır. Görünür kalınlığı 5 m’yi bulan eolinit Pliyosen yaşlı kumlu kil birimleri üzerinde uyumsuz olarak oturmaktadır (Şekil 2c). Çalışma kapsamında, eoliyen kumlarla örtülü eolinit tabakalarının örttüğü paleo-topoğrafyayı ortaya koymak amacıyla üç farklı hat boyunca 9 derinlik seviyesi ve Dipol-dipol elektrot dizilimi kullanılarak EÖT çalışması gerçekleştirilmiştir
(Şekil 3c). Elektrik özdirenç hatları, Pliyosen yaşlı birim üzerindeki en kalın eolinit birimleri göz önüne alınarak, elektrot aralığ1 $5.5 \mathrm{~m}$ ve hat uzunluğu $110 \mathrm{~m}$ olacak şekilde seçilmiştir. Ters çözüm işleminde, Bozcaada eoliniti örneğinde de belirtildiği gibi, bu çalışmaya da konu olan jeolojik birimler arasında keskin özdirenç geçişleri öngörüldüğünden L1 normu ters çözüm yaklaşımı kullanılmıştır.

Elde edilen yerelektrik kesitler (Şekil 7) incelendiğinde, eolinit ve altında bulunan Pliyosen yaşlı kumlu-killli kırmızımsı renkteki birim arasındaki litolojik geçiş açıkça görülmektedir. Yaklaşık $12 \mathrm{~m}$ derinliğe kadarki özdirenç değişimini gösteren kesitlerin üst kısımlarındaki yüksek özdirençli birim eoliniti, daha derinlerdeki düşük özdirençli birimler ise Pliyosen yaşlı kumlu ve killi birimleri göstermektedir (Şekil 7). Bu iki birim arasındaki yüksek özdirenç zıtlığı üç kesitte de belirgin bir şekilde görülebilmektedir. KDGB yönelimli bu kesitlere göre, eolinit biriminin kalınlığı 3.5 ve $8 \mathrm{~m}$ arasında değişmektedir. P1 ve P2 kesitlerinde bu iki birim arasındaki geçiş daha keskin bir şekilde gözlenirken P3 kesitinde ise iki birim arasındaki geçişin derinlikle birlikte dereceli olarak değiştiği görülmektedir (Şekil 7). Bununla birlikte, alt kesimde bulunan pekleşmemiş kumlu birim içinde küçük bir gömülü paleo-vadinin varlığ1 da gözlenmektedir (Erginal vd. 2013b). $\mathrm{Bu}$ sebeple, yerelektrik kesitler eolinit kumları ile fosilleşmiş 5-9 m derinliklerde inişli çıkışlı bir topoğrafya sergilemektedir. Eolinitin karaya doğru genişliği doğudan batıya doğru azalmaktadır (Şekil 7). Bu azalma muhtemelen çimentolanma öncesi kıyı kumul istifinin orijinal genişliğini göstermektedir. Diğer taraftan, yerelektrik hattın karaya doğru olan kesiminin sonlarında özdirenç değerlerindeki keskin düşüş eolinitin kıyı gerisindeki sınırını (100-105 m) belirlemektedir (Erginal vd. 2013b). 


\section{Kıyıköy Yalıtaşı}

Kırklareli ili sınırları içerisinde Kıyıköy (Şekil 1) yerleşiminin doğu kıyısında bulunan çalışma alanı Karadeniz kıyılarında bugüne dek ilk defa gözlenen yalıtaşlarını (Şekil 2d) konu almaktadır. Yalıtaşı oluşumu ile gel-git genliği arasındaki ilişki düşünüldüğünde gömülü yalıtaşı tabakalarının kalınlığının bilinmesi deniz suyu seviyesi değişimleri hakkında önemli bilgiler verebilmektedir.

Çalışma alanında ve çevresinde genel olarak kumtaşı ve kiltaşı ardalanmalı Orta-Geç Eosen yaşlı fosilli kireçtaşı bileşimi içeren jeolojik birimler bulunmaktadır (Erginal vd. 2013c). Kıyı boyunca yüzeyleyen yalıtaşı tabakalarının maksimum görünür kalınlığı yaklaşık $75 \mathrm{~cm}$ olmasına rağmen plaj kumları altında örtülü kısmı da dahil edildiğinde denize doğru 2 m'yi bulduğu, ayrıca 20 m açığa kadar (su altında) devam ettiği gözlenmektedir.

Bu çalışmada, deniz kıyısına dik $10 \mathrm{~m}$ aralıklı 4 farklı hat boyunca gömülü yalıtaşlarının yüzeyaltı yapısı ve kıyı çizgisinden karaya doğru plaj kumları altındaki uzanımlarının belirlenebilmesi amacıyla EÖT çalışması gerçekleştirilmiştir (Şekil 3d). Saha koşullarını ve hedef birimin öngörülen kalınlık miktarını dikkate alarak, Dipol-dipol dizilimi ile 11 derinlik seviyesi boyunca 22 istasyonda ilk iki hat için (P1 ve P2) $1 \mathrm{~m}$ elektrot aralığı kullanılırken diğer iki hat (P3 ve P4) için $1.5 \mathrm{~m}$ elektrot aralığ 1 seçilmiştir. $\mathrm{Bu}$ çalışmada da Karaburun kokunitleri örneğindekine benzer olarak L2 normu 2B ters çözüm algoritması kullanılmıştır (Loke ve Barker 1996). $\mathrm{P} 1$ ve $\mathrm{P} 2$ kesitlerinin aksine $\mathrm{P} 3$ ve $\mathrm{P} 4$ kesitlerinin sonlarına doğru belirgin bir topoğrafik değişim bulunduğundan bu hatlarda elektrot noktalarına ait yükseklik değerleri de ölçülerek ters çözüm işleminde hesaba katılmıştır.

Elde edilen P1 ve P2 kesitleri $2.7 \mathrm{~m}$ derinliğe kadar özdirenç değişimlerini gösterirken P3 ve P4 kesitleri ise $4 \mathrm{~m}$ derinliğe kadar bilgi içermektedir. Yerelektrik kesitlerde özdirenç değerleri 1 ile 550 ohm.m arasında değişmektedir (Şekil 8). Dolayısıyla, yüksek özdirençli yalıtaşı tabakaları ile plaj materyalleri arasındaki özdirenç farklılığ 1 belirgin bir şekilde ayırt edilebilmektedir (Erginal vd. 2013c). Özdirenç değerlerindeki aşırı düşüş ise deniz suyu girişiminden kaynaklı tuzluluk artışı ile ilgili olmalıdır. Kesitlerde, plaj kumları altındaki yalıtaşı bloklarının yaklaşık $1 \mathrm{~m}$ kalınlığına sahip olduğu ve bu derinlikten sonra aniden sonlandıkları görülmektedir (Şekil 8). Bununla birlikte, P3 ve P4 kesitlerinin son kesimlerindeki yüksek özdirençli alanların kıyı gerisinde bulunan fosil kumulların varlığ ile ilişkilendirilmektedir. Yerelektrik kesitlere göre, gömülü yalıtaşı blokları karaya doğru $23 \mathrm{~m}$ mesafeye kadar uzanmaktadır (Şekil 8). Diğer taraftan kesitin başlangıç kısımlarında yalıtaşı bloklarına ait izlerin görülmemesi o kısımda tabaka başlarındaki dalga aşındırmasından kaynaklanmış olmalıdır. Sonuç olarak bu alanda jeofizik veriler 1şı̆̆ında iki önemli bulgu tespit edilmiştir. Bunlardan ilki, yalıtaşı tabakalarının gömülü ve yüzlek veren kısımlarının birlikte maksimum kalınlığının 1.75 m olduğudur. Bu kalınlık değeri Goudie (2001)'de belirtilen Karadeniz'deki gelgit genliğini aşmaktadır. Bir diğeri ise, deniz içerisinde ve kıyıda çimentolanmış bu birimlerin yaklaşık $40 \mathrm{~m}$ genişliğine sahip olduğudur (Erginal vd. 2013c). 


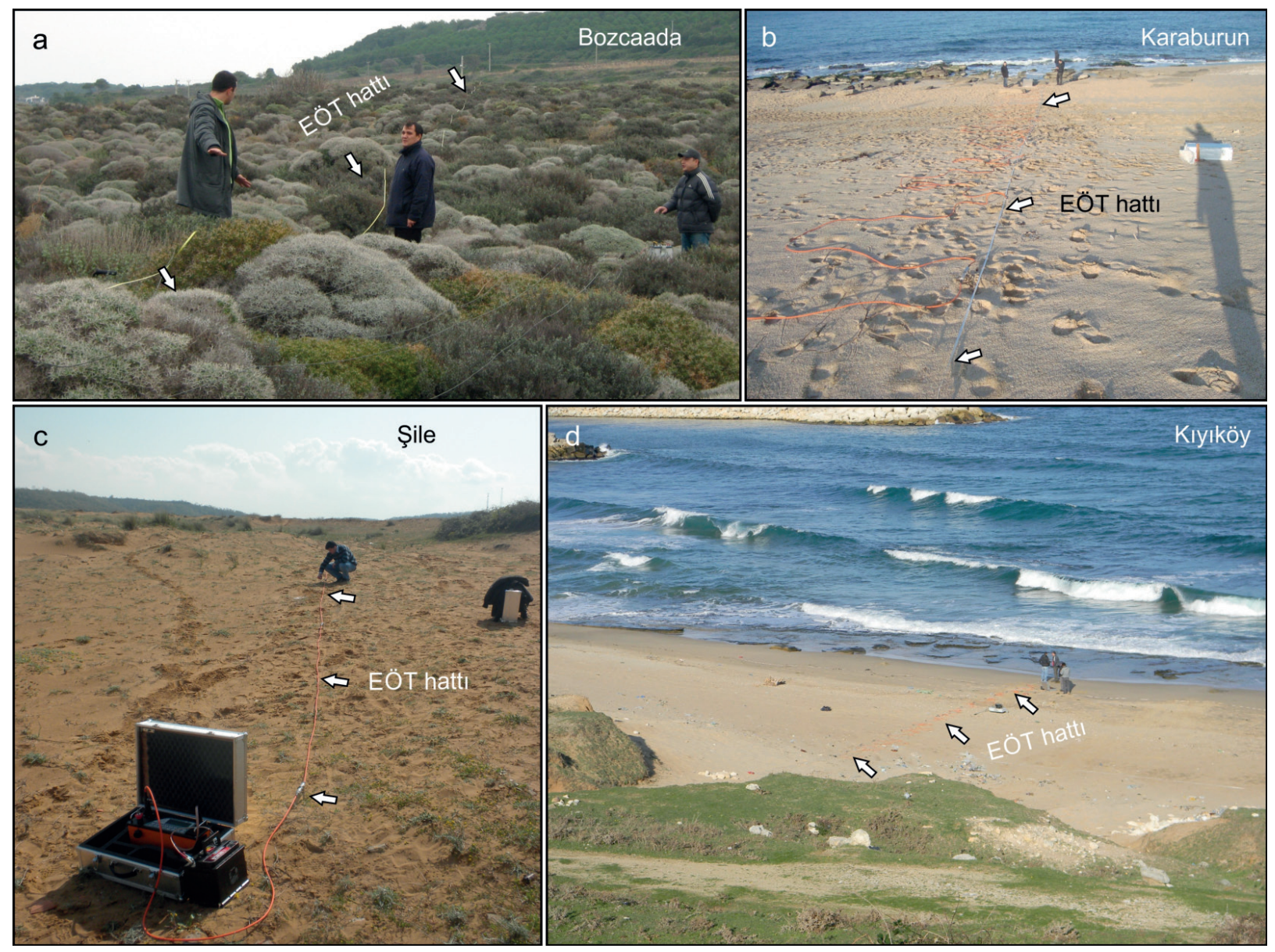

Şekil 3. a) Bozcaada, b) Karaburun, c) Şile ve d) Kıyıköy kıyılarında yapılan EÖT çalışmalarına ait bazı ölçüm hatları.

Figure 3. Some measurement profiles of ERT surveys performed on a) Bozcaada, b) Karaburun, c) Şile and d) Kiylköy coasts.

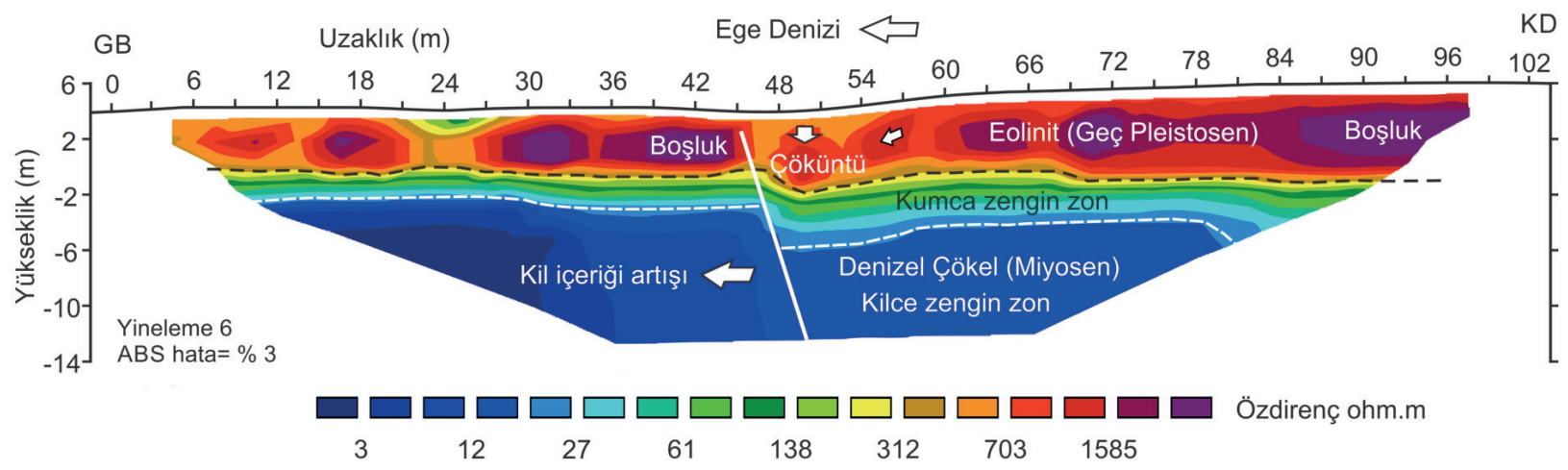

Şekil 4. Bozcaada eoliniti üzerinde alınan hatta ait yerelektrik kesit.

Figure 4. Inverse model resistivity section of the profile obtained from the Bozcaada eolianite 

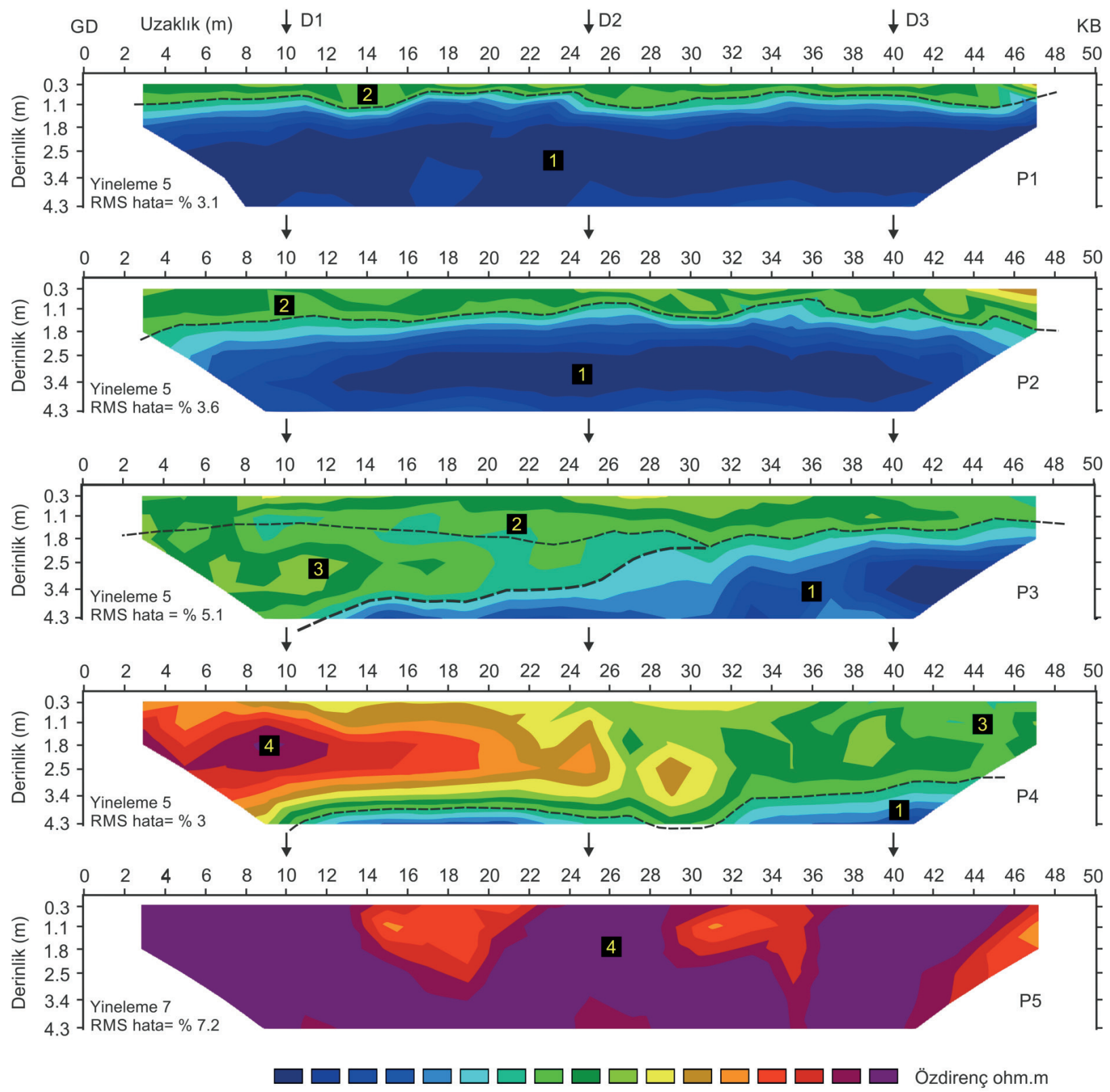

$\begin{array}{llllllll}4 & 10 & 30 & 60 & 120 & 250 & 500 & 1020\end{array}$

1 Deniz suyuna doygun plaj materyali 2 Kokina 3 Doymamış plaj materyali

4 Deniz suyuna doygun ve doymamış plaj materyali arasındaki geçiş zonu

Şekil 5. Karaburun kokina plajında kıyı çizgisine paralel alınan hatlara ait yerelektrik kesitler.

Figure 5. Inverse model resistivity sections of the profiles taken parallel to the coastline at Karaburun coquina beach. 

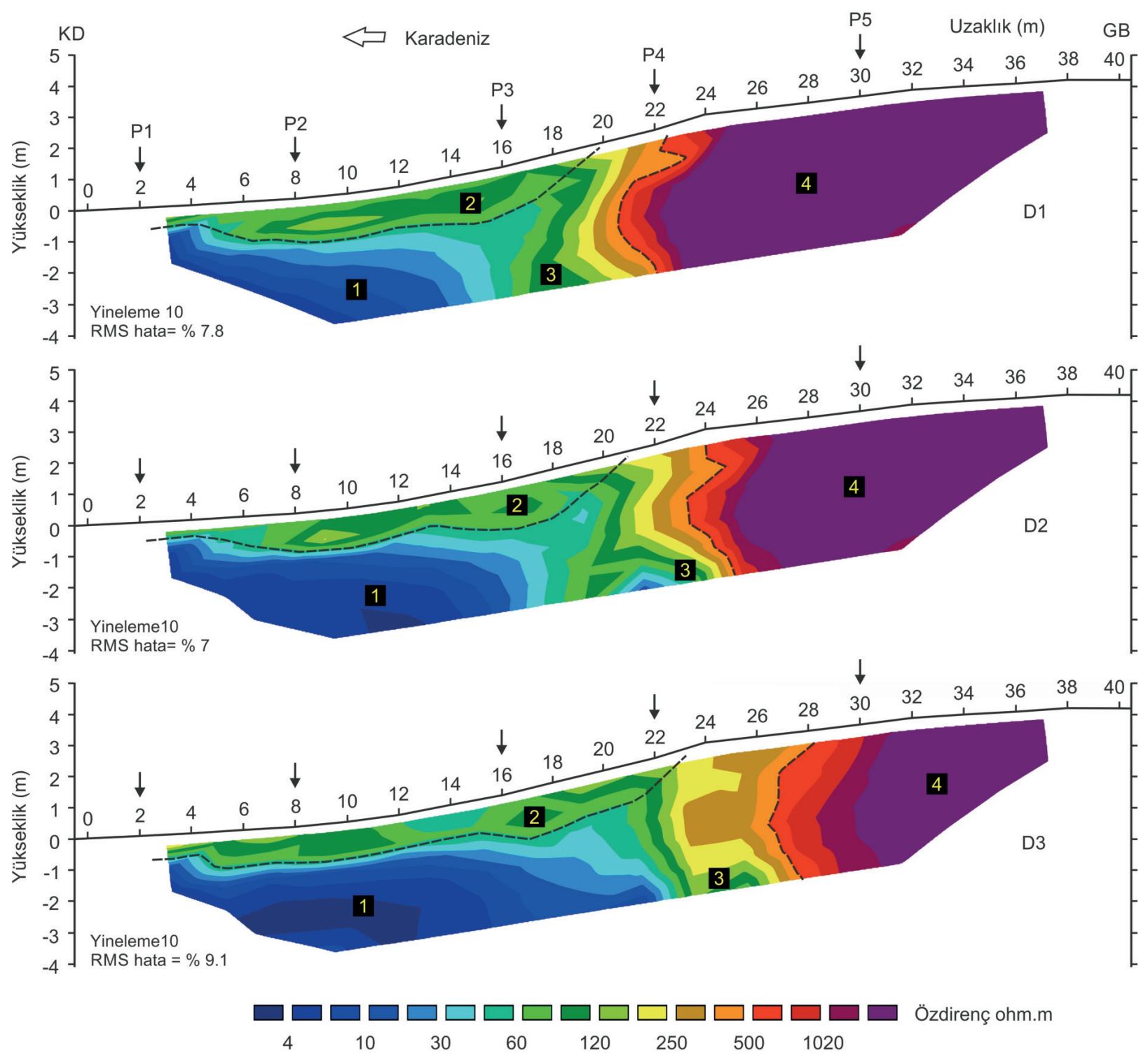

1 Deniz suyuna doygun plaj materyali $\quad 2$ Kokina $\quad 3$ Doymamış plaj materyali

4 Deniz suyuna doygun ve doymamıs plaj materyali arasındaki geçiş zonu

Şekil 6. Karaburun kokina plajında kıyı çizgisine dik alınan hatlara ait yerelektrik kesitler.

Figure 6. Inverse model resistivity sections of the profiles taken perpendicular to the coastline at Karaburun coquina beach. 



Şekil 7. Şile eoliniti üzerinde alınan hatlara ait yerelektrik kesitler.

Figure 7. Inverse model resistivity sections of the profiles obtained from the Sile eolianite. 



Şekil 8. Kıyıköy yalıtaşı üzerinde alınan hatlara ait yerelektrik kesitler.

Figure 8. Inverse model resistivity sections of the profiles obtained from the Klylköy beachrock.

\section{SONUÇLAR}

Bu çalışmada özellikle sı̆̆ amaçlı jeofizik araştırmalarda oldukça sık ve başarılı bir şekilde kullanılan EÖT tekniğinin geleneksel olmayan kullanım alanları üzerindeki uygulama örnekleri sunulmuştur. Jeofizik görüntüleme yöntemi plaj ve kumul kumları altında gömülü çimentolanmış plaj ve kumul istiflerine ilk kez uygulanarak çimentolanmış kıyı istiflerinin yüzeyaltı yapılarına ait somut sonuçlar elde edilmiştir. Sunulan örneklerde farklı kıyı istiflerinin fiziksel özellikleri (tabaka kalınlığ1, derinlik, yüzey alt1 geometrisi ve dokunak ilişkisi vb.) 2B EÖT çalışmalarıyla belirlenmiştir. Elektrik özdirenç yöntemi bu istiflerin alt ve üstünde bulunan diğer jeolojik formasyonlarla dokunak ilişkilerinin belirlenmesi yanında kıyı morfodinamiklerinin anlaşılması açısından da önemli ipuçları vermektedir. Nitekim, yalıtaşlarının gel-git içi ortamda çimentolanma özelliği değerlendirilirken tabaka kalınlığının gel-git genliğini aşmaması 
beklenir. Plaj materyalleri altında gömülü olan tabakalar yüzeyleyen kısımlara eklendiğinde gel-git genliği aşıllyorsa bu durumda kıyı gerisi (supratidal) ortamda meteorik çimentolanmanın da gel-git içi (intertidal) çimentolanmaya katk1 koyduğu anlaşılır. Bu da yüzeylenmiş ve gömülü kısımların toplam kalınlığı ile anlaşılabileceğinden EÖT yüzeyaltı görüntüleme aracı olarak önemli katkı vermektedir. Aynı şekilde eolinitler gibi fosil kumul istifleri jeolojik geçmişte kıyıdaki paleo-rüzgar sistemlerinin kara yönünde yaptığ1 biriktirme sonucunda oluşurlar. Tabakaların çapraz tabakalı yapısı rüzgarın esiş yönü hakkında bilgi verirken kalınlığı o dönemki kum tepeleri ve sırtlarının yüksekliğini ortaya koyar. Tabakaların örttüğü paleo-topoğrafya yüzeyi ise kumul istilasına uğrayan eski morfolojik düzlemi (jeolojik açıdan diskordans yüzeyini) belirtir. Bu nedenle EÖT fosil kumul sistemlerinin geliştiği paleo-kıyı ortamının derindeki izlerini açığa çıkarmaktadır. $\mathrm{Bu}$ sonuçlar kıyı jeolojisi ve jeomorfolojisi araştırmalarında fosil topoğrafyalar ve istif morfometrisinin anlaşılmasında jeofizik yöntemlerin katkılarını göstermektedir.

\section{KATKI BELİRTME}

$\mathrm{Bu}$ çalışmalar esnasında Çanakkale Onsekiz Mart Üniversitesi, Jeofizik Mühendisliği Bölüm Başkanlığı'nı sırasıyla yürüten Tolga Bekler ve Aydın Büyüksaraç'a elektrik özdirenç cihazlarının kullanımı için gösterdikleri anlayıştan ötürü teşekkürlerimizi sunarız. Arazi çalışmalarındaki özverili katkılarından dolayı Mustafa Avcıŏlu, Erdal Öztura, Rezzan Ekinci ve Hakan Kaya'ya teşekkür ederiz. Makalenin son haline gelmesindeki katkılarından dolayı Prof. Dr. Hüseyin Y1lmaz ve ismi belirtilmeyen diğer hakeme teşekkürlerimizi sunarız. Üçüncü yazar (AEE) 112Y217 ve 113Y418 nolu projeler kapsamında TÜBİTAK'a, GEBİP ödül programı kapsamındaki destekleri için ise Türkiye Bilimler Akademisi'ne (TÜBA) teşekkür eder. Şekil 1'in oluşturulmasında GMT (Wessel ve Smith 1995) yazılımı kullanılmıştır.

\section{EXTENDED SUMMARY}

It is well known that both shallow and deeper subsurfacestructuresmaybeinvestigated in success by performing geophysical imaging surveys. ERT is one of the efficient imaging technique to provide a physical contrast between different lithological units. Additionally the rapid improvements of the software packages and multi-electrode measuring systems during the last decade have enabled to perform the ERT measurements more widely, faster and more reliable. Thus the technique is frequently performed on many investigations to delineate the nature of the subsurface.

To the contrary of the researchers paying much attention to the archaeological, hydrogeological, environmental and structural geological problems such as exploring the buried archaeological remains, investigating shallow aquifers, groundwater contaminations and the seawater intrusions, mapping the landfill areas and karstic cavities, geologic contacts and the faults and also the soil-bedrock interfaces etc., there are rare special investigations in all over the world that have been performed to shed light to paleoenvironmental studies and buried topography investigations or imaging the sedimentary structures on coastal areas. Despite this rareness some recent case studies, which have provided successful contributions in understanding the nature of Quaternary coastal deposits by using ERT technique, were performed in some different parts of Turkey. These studies aimed to obtain some new findings about Late Pleistocene/Holocene sea level changes by investigating special coastal 
deposits developed with the control of the wavecurrent and wind. The case studies presented herein were performed in Black Sea (Şile, Karaburun, Kıyı köy), and Aegean Sea (Bozcaada Island) coasts of Turkey. Measured apparent resistivity data sets obtained along the survey profiles were inverted using $2 D$ inversion schemes to determine the true resistivity distribution of the subsurface. The derived tomographic images clearly indicated the subsurface geometry, contact relationship and depositional characteristics of the consolidated coastal deposits such as eolianite, coquinite and beachrocks, which result from different bedded Quaternary carbonate cementation. The physical parameters such as depths and the thicknesses of these consolidated coastal deposits were also revealed. Therefore it can be mentioned that imaging the lower parts of the beach and dune sands (or other covering units) of layered coastal deposits, which were cemented with calcium carbonate after the development by the control of wave, current and wind, and also the buried geological structures and fossil topographies covered by those beach and dune sands, shows the significant contribution of ERT technique on the investigations of coastal geology and paleo-geography. As a result, these studies also showed that application of ERT technique can be an efficient tool for paleoenvironmental studies on coastal areas provided that the electrical resistivity contrasts between the consolidated coastal deposits (eolianite, coquinite and beachrocks) and underlying-overlying beach materials are measurable.

\section{DEĞİNILEN BELGELER}

Allaby, M. 2008. A Dictionary of Earth Sciences, Oxford University Press, New York.

Avşarcan, B. 1997. Yalıtaşı oluşumu üzerine teoriler ve Türkiye kıyılarındaki yalıtaşlarının bazı özellikleri, İstanbul Üniversitesi Coğrafya Dergisi 5, 259-282.
Bener, M. 1974. Alanya-Gazipaşa arasındaki kıyı kesiminde yalıtaşı oluşumu, İstanbul Üniversitesi Coğrafya Enstitüsü Yayınları, no. 75.

Bezerra, F.H.R., Lima-Filho, F.P., Amaral, R.F., Caldas, L.H.O. ve Costa-Neto, L.X. 1998. Holocene coastal tectonics: coastal tectonics, Special Publication, vol:146, eds: Stewart, I.S., Vitafinzi, C., Geological Society, London, 279-293.

Binkley, K.L., Wilkinson, B.H. ve Owen, R.M. 1980. Vadose beachrock cementation along a Southeastern Michigan marl lake, Journal of Sedimentary Petrology 50, 953-962.

Bricker, O.P. 1971. Introduction: beachrock and intertidal cement: Carbonate Cements: 1-3, ed: Bricker, O.P., John Hopkins Press, Baltimore, M.D

Brooke B. 2001. The distribution of carbonate eolianite, EarthScience Reviews 55, 135-164.

Desruelles, S., Fouache, E., Ciner, A., Dalongeville, R., Pavlopoulos, K., Kosun, E., Coquinot, Y. ve Potdevin, J-L. 2009. Beachrocks and sea-level changes since Middle Holocene: comparison between the insular group of Mykonos-DelosRhenia (Cyclades, Greece) and the southern coast of Turkey, Global and Planetary Change 66, 19-33.

Ekinci, Y.L., Demirci, A., Erginal, A.E. ve Öztürk, B. 2010. Detection of cavities in carbonate-cemented fossil eolian sand dunes using DC electrical resistivity survey, Bozcaada Island, Turkey, European Geosciences Union General Assembly, Geophysical Research Abstracts, v. 12, EGU2010-7005.

Ekinci, Y.L., Demirci, A., Erginal., A., Kaya, H. ve Ekinci, R. 2012. The nature and subsurface geometry of Late Holocene Coquina rocks, Karaburun-İstanbul, NW Turkey, European Geosciences Union General Assembly, Geophysical Research Abstracts, v. 14, EGU2012-9367.

Erginal, A.E., Kıyak, N.G., Bozcu, M., Ertek, T.A., Güngüneş, H., Sungur, A. ve Türker, G. 2008. On the origin and age of Arıburnu beachrock, Gelibolu Peninsula, Turkey, Turkish Journal of Earth Sciences 17, 803-819.

Erginal, A.E., Kıyak, N.G. ve Öztürk, B. 2010. Investigation of beachrock using microanalyses and OSL dating: A case study from the Bozcaada Island, Turkey, Journal of Coastal Research 26 (2), 350-358.

Erginal A. E., Ekinci Y. L., Demirci A., Elmas E. K. ve Kaya K. 2012. First note on Holocene coquinite on Thrace (Black Sea) coast of Turkey, Sedimentary Geology 267-268, 55-62.

Erginal, A.E. 2012. Beachrock as evidence of sea-level lowstand during the Clasical period, Parion antique city, Marmara Sea, Turkey, Geodinamica Acta 25, 96-103.

Erginal, A.E., Ekinci, Y.L., Demirci, A., Avcioglu, M., Ozturk, M.Z., Turkes, M. ve Yigitbas, E. 2013a. Depositional characteri stics of carbonate-cemented fossil eolian sand dunes, Bozcaada Island, Turkey, Journal of Coastal Research 29 (1), 78-85. 
Erginal, A.E., Kiyak, N.G., Ekinci, Y.L., Demirci, A., Ertek, A. ve Canel, T. 2013b. Age, composition and paleoenvironmental significance of a late Pleistocene eolianite from the western Black Sea coast of Turkey, Quaternary International 296, 168-175.

Erginal, A.E., Ekinci, Y.L., Demirci, A., Bozcu, M., Ozturk, M.Z., Avcioglu, M. ve Oztura, M.Z. 2013c. First record of beachrock on Black Sea coast of Turkey: Implications for Late Holocene sea-level fluctuations, Sedimentary Geology 294, 294-302.

Erol, O. 1972. Gelibolu Yarımadası kıyılarında yalıtaşı oluşumları, Ankara Üniversitesi Coğrafya Dergisi 3-4, 1-2.

Frebourg G., Hasler C., Le Guern P. ve Davaud E. 2008. Facies characteristics and diversity in carbonate eolianites, Facies 54 (2), 175-191.

Ginsburg, R.N. 1953. Beachrock in South Florida, Journal of Sedimentary Petrology 23, 85-92.

Goudie, A. 1966. A preliminary examination of the beach conglomerates of Arsuz, South Turkey, Geographical Articles 6, 6-9.

Goudie, A. S. 2001. The Nature of the Environment, WileyBlackwell, Oxford.

Kelletat, D. 2006. Beachrock as a sea-level indicator? Remarks from a geomorphological point of view, Journal of Coastal Research 22 (6), 1555-1564.

Kıyak, N.G. ve Erginal, A.E. 2010. Optical stimulated luminescence dating study of Eolianite on the Island of Bozcaada, Turkey: preliminary results, Journal of Coastal Research $26(4), 673-680$.

Kneale, D. ve Viles, H.A. 2000. Beach cement: incipient CaCO3cemented beachrock development in the upper intertidal zone, North Uist, Scotland, Sedimentary Geology 132, $165-170$.

Loke, M.H. ve Barker, R.D. 1996. Rapid least-squares inversion of apparent resistivity pseudosections using a quasiNewton method, Geophysical Prospecting 44, 131-152.

Loke, M.H., Acworth, I. ve Dahlin, T. 2003. A comparison of smooth and blocky inversion methods in 2D electrical resistivity imaging, Exploration Geophysics 34, 182-187.

Loope D.B. 2009. Eolianite, Encyclopedia of Paleo-climatology and Ancient Environments, ed: Gornitz, V., Springer, Dordrecht-The Netherlands, 319-320.

Lovejoy, D.W. 1998. Classic exposures of the Anastasia Formation in Martin and Palm Beach Counties, Florida, Miami Geological Society Publications, Miami-Florida.

McLaren, S. 2004. Aeolianite, Enclopedia of Geomorphology, ed: Andrew S. Goudie, Routledge, New York.

Neumeier, U. 1998. Le rôle de l'activité microbienne dans la cimentation précoce des beachrocks (sédiments intertidaux), Terra Environ 12, 1-183.
Polymeris, G.S., Erginal, A.E. ve Kiyak, N.G. 2012. A comperative morphology, compositional as well as TL study of Bozcaada (Tenedos) and Şile aeolianites, Turkey, Mediterranean Archaeology \& Archaeometry 12 (2), 117-131

Ramsay, P.J. ve Cooper, J.A.G. 2002. Late Quaternary sea level changes in South Africa, Quaternary Research 57, 82-90.

Rey, D., Rubio, B., Bernabeu, A.M. ve Vilas, F. 2004. Formation, exposure, and evolution of a high-latitude beachrock in the intertidal zone of the Corrubedo complex (Ria de Arousa, Galicia, NW Spain). Sedimentary Geology 169 (1-2), 93-105.

Russel, R.J. 1959. Carribean beach-rock observations, Zeitschrift für Geomorphologie. 3 (3), 227-236.

Sasaki, Y. 1992. Resolution of resistivity tomography inferred from numerical simulation, Geophysical Prospecting 40, 453-464.

Scholle P.A., Bebout D.G. ve Moore C.H. 1983. Carbonate Depositional Environments, Memoir no. 33, American Association of Petroleum Geologists, Tulsa-Oklahoma.

Shen J-W., Long J-P., Pedoja K., Yang H-Q., Xu H-L. ve Sun J-L. 2013. Holocene coquina beachrock from Haishan Island, east coast of Guangdong Province, China, Quaternary International, (baskıda), 1-19.

Spratt, T.A.B. ve Forbes, E. 1847. Travels in Lycia, Milyas, and the Cibyratis. II.-John Van Voorst, Paternoster Row, London.

Thomas, P.J. 2009. Luminescence dating of beachrock in the Southeast Coast of India-potential for Holocene shoreline reconstruction, Journal of Coastal Research 26 (1), 1-7.

Vousdoukas, M.I., Velegrakis, A.F. ve Plomaritis, T.A. 2007. Beachrock occurrence, characteristics, formation and impacts, Earth Science Reviews 85, 23-46.

Wessel, P. ve Smith, W.H.F. 1995. New version of the Generic Mapping Tools, Eos Transactions, American Geophysical Union 76, 329-329.

Zenkovitch, V.P. 1967. Processes of Coastal development, Oliver \& Boyd, London.

$\begin{array}{ll}\text { Makale Geliş Tarihi } & : \text { 28 Ağustos } 2014 \\ \text { Kabul Tarihi } & : \text { 13 Ekim } 2014 \\ \text { Received } & : \text { 28 August } 2014 \\ \text { Accepted } & : \text { 13 October } 2014\end{array}$

